\title{
REVIEW OF METHODS AND TECHNIQUES FOR THE ASSESMENT OF WINDS AT PEDESTRIAN LEVEL
}

\author{
K.Mohan ${ }^{1}$ \\ ${ }^{I}$ Senior Professor, Gitam School of Architecture, Gitam University, Visakhapatnam, Andhra Pradesh, India
}

\begin{abstract}
Wind tunnel tests for assessing Pedestrian Level Winds (PLWs) are usually performed for existing new developments, especially tall buildings. Tall buildings can deflect high velocity upper level winds towards the ground creating high wind speeds at pedestrian level which could affect the comfort and safety of pedestrians. Auckland, Wellington and several other cities such as Tokyo, Karlsruhe, Toronto etc., insist on wind tunnel tests for tall buildings prior to granting approval. Since there is an increase in tall building activity in India, it is now being realized that they need to be assessed for favorable PLWs.
\end{abstract}

With the construction of boundary layer wind tunnels in many cities around the world after the 1960s and the introduction of sophisticated probes and measurement techniques such as the erosion technique, etc., it is now possible to measure wind speeds over large areas. This paper gives an overview of the state of the art wind laboratory methods and techniques that are presently being used for assessing pedestrian level winds.

Keywords: Pedestrian Discomfort, Point Methods, Area Methods, Erosion Technique

\section{INTRODUCTION}

Tall buildings tend to divert strong upper level winds to the ground. This gives rise to high velocity winds at pedestrian level that could create pedestrian discomfort or even compromise the safety of pedestrians. Auckland, Wellington and several other cities such as Tokyo, Karlsruhe, etc., Toronto etc., insist on wind tunnel tests for tall buildings prior to granting approval. Since there is an increase in tall building activity in India, it is now being realized that they need to be assessed for favorable Pedestrian Level Winds (PLWs).

Several methods and techniques exist for carrying out wind tunnel investigations in boundary layer wind tunnels. This paper provides an overview of some of the techniques that are currently employed in wind tunnel laboratories for the assessment of PLWs.

\section{MEASUREMENT TECHNIQUES}

Many simple and sophisticated methods are used for assessing pedestrian level winds in boundary layer wind tunnels. Commonly used methods include the use of hot wires or hot films, cobra probes, Irwin probes and the erosion technique. Newer methods such as infra-red thermography have also been used by Yamada et al. [1] and $\mathrm{Wu}$ and Stathopoulos [2] for pedestrian wind valuations.

Measurement of mean wind speeds at various locations near the ground as well as gust speeds are the minimum requirement for the assessment of pedestrian winds in boundary layer wind tunnels [1]. Since winds at a low height affect pedestrians, wind measurements at ground level are usually taken for assessing PLWs [3]. In the wind tunnel the instruments as well as the model should not block or disturb the simulated wind flow. Accuracy, repeatability, stability, cost and availability are factors that should be considered in the selection of an appropriate experimental technique [4].

\section{POINT METHODS}

There are two classes of measurement that can be defined in pedestrian wind studies: point methods and area methods. Point measurements are generally taken in wind tunnel investigations to quantify changes in wind speed. However with this method quantitative data of wind speeds only at specific points in a study area can be obtained. When the wind environment has to be assessed for large developments, this method becomes laborious and time consuming. Combining point measurements with area measurements for studies involving housing neighborhoods, urban parks, etc which gives a holistic picture of the wind environment is a much better option.

\subsection{Laser-Doppler Anemometry}

The velocity of fluids can be measured accurately with a Laser Doppler Anemometer which uses two laser beams which cross each other in the wind flow and finds the Doppler frequency shift of laser light that is scattered by particles in the moving air [3]. This is a non-intrusive measuring technique and does not require calibration. Flow reversals which occur in turbulent flows can be measured by a Laser Doppler Anemometer. A view of the Laser Doppler Annemometer from Dantec Dynamics [5] is shown in Fig.1. Laser Doppler Anemometers, being expensive, are mainly used for research purposes. 


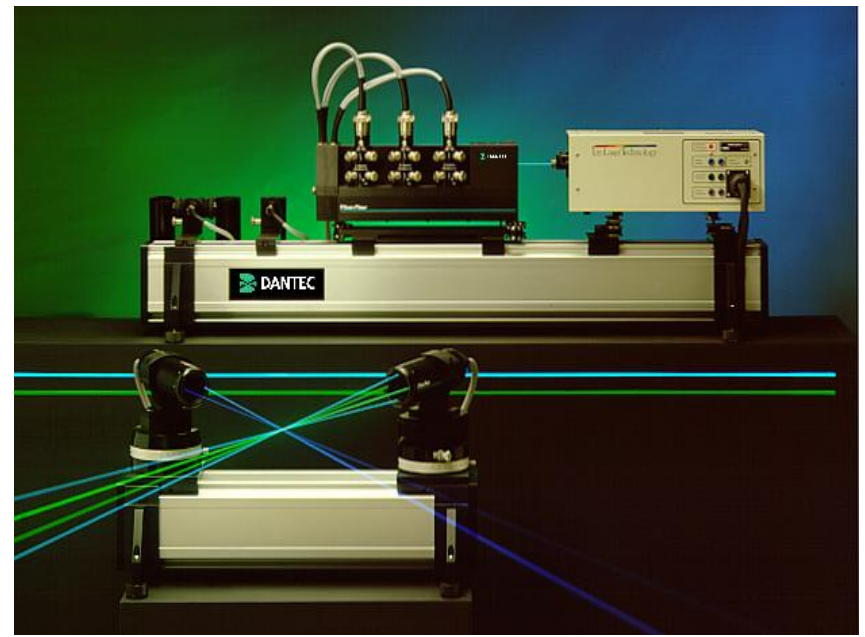

Fig-1: View of Laser-Doppler Annemometer- Source: [5]

\subsection{Infrared- Thermography Technique}

The Infrared- Thremography Technique captures the advantages of both the point as well as the area methods. Yamada et al [1] and $\mathrm{Wu}$ and Stathopoulos [6] have used this technique for measuring PLWs. According to $\mathrm{Wu}$ and Stathopoulos this technique utilizes the fact that there exists a relationship between the heat transferred from the surface of a body and the wind flow in its vicinity. In this technique thermal images are obtained of temperature distributions on the surface floor of the wind tunnel on which the model is placed. $\mathrm{Wu}$ and Stathopolous have used the infrared thermography technique for assessing PLWs for various building configurations. They conclude that this technique should be used for studying the wind impact in a holistic manner over the entire wind field and not just at some specific points [6].

\subsection{Particle Image Velocimetry}

Particle Image Velocimetry is an accurate, non-intrusive technique that is yet to find routine applications in pedestrian wind assessments. It is mainly used for research purposes and in industrial applications. In this technique particles in a flow are illuminated by a light sheet or laser. The motion of particles between two images by a digital camera is used to calculate the speed of winds in the flow field.

\subsection{Hot Wire Anemometer and Hot Film Probes}

Hot Wire Anemometers and Hot Film Probes are widely used in the investigation of pedestrian level winds, especially for obtaining wind speed measurements at specific points on a development model. Figure 2 shows a hot film probe used for recording wind speed measurements. These probes consist of extremely thin wire or film fixed between two prongs. According to Kepka [7] when air passes around the wire a cooling effect is produced, which when quantified gives a measure of the wind speed. Though accurate results are obtained the hot wires need to be calibrated often. In highly turbulent flows the, results from the hot wires may give wrong results [8].

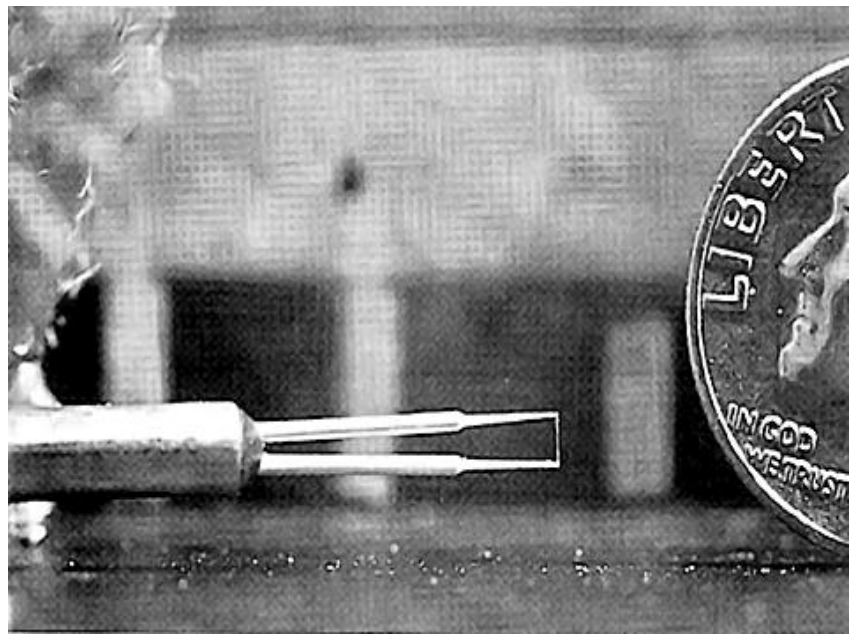

Fig-2: Hot film probe used for recording point wind speed measurements- Source: [3]

\subsection{Irwin Probe}

The Irwin probe developed by Irwin [9] is a rugged Omnidirectional probe frequently used for measuring pedestrian level winds. Pressure difference between the end of a hole of a tube projecting out from the probe and the bottom end of another tube in the probe is used for determining PLWs. However like the hot-films and hot wires, only the horizontal component of wind flow can be measured by the Irwin probe. A comparison study of wind measurements made with Hot Film and Irwin Probe by $\mathrm{Wu}$ and Stahopoulos [2] has shown good agreement between the results obtained from the two instruments According to Cermak [4] the probe is sufficiently accurate for pedestrian wind studies. Fig. 3 shows Irwin probes used for measuring the wind speeds in the balconies of the model of the Burj Dubai Tower [10].

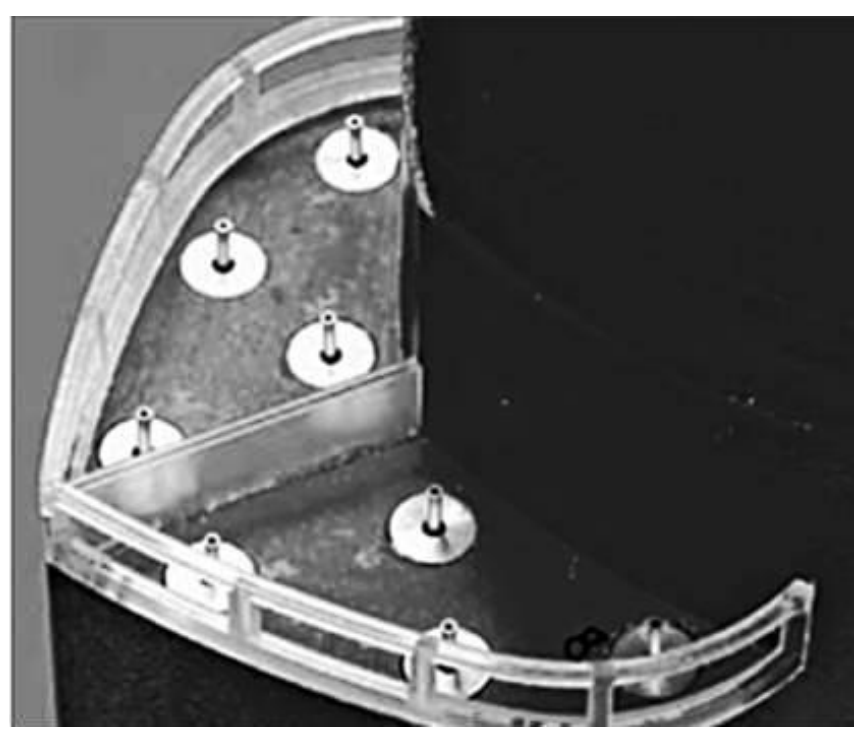

Fig-3: View of Irwin probes in the balconies of the model of Burj Dubai Tower- Source: [10]. 


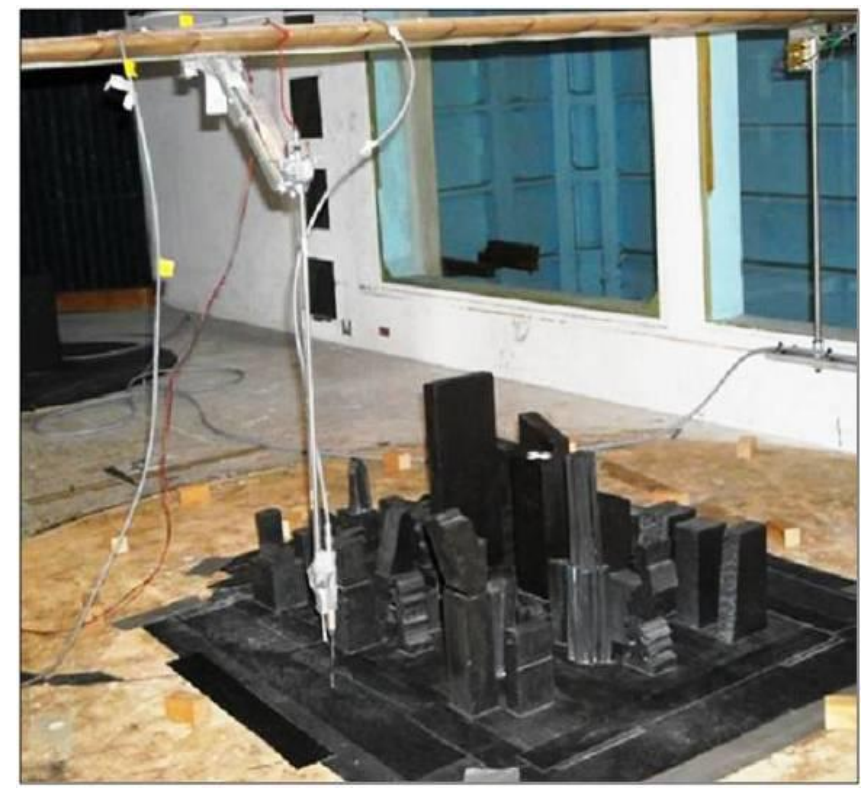

Fig-4: Point measurements being taken by a cobra probe in a model of tall buildings. Source: [12].

\subsection{Cobra Probe}

The cobra probe is a multi-hole pressure probe that provides dynamic three component velocity and local static measurements in real time [11]. Computer programs make it possible to move the cobra probe to required locations for measuring PLWs. The computer controlled traversing rig shown in Fig. 4 makes it convenient to take wind measurements at different points on models of single buildings or in the spaces such as courtyards entrances and roads [10].

\section{AREA METHODS}

Area methods provide continuous information of windiness over a broad area, as opposed to the quantitative techniques which provide wind speeds at specific points. Conducting a test with an area method like the erosion test minimizes the risk of neglecting to identify areas of importance. Regulations in certain cities, such as Wellington require both area and point measurements to be done as part of a full wind tunnel simulation of a new development [7].

\subsection{Flow Visualization Using Smoke}

The shortcoming of the point methods, which provide quantitative data at specific points only, can be mitigated by making the flow visible by the introduction of non toxic smoke into the flow around the model buildings in the wind tunnel. This is a common technique typically combined with the point methods. Many of the important wind flows such as downwash etc., (Fig.5) which influence pedestrian comfort at street level, can be identified by observing the smoke flow patterns [3]

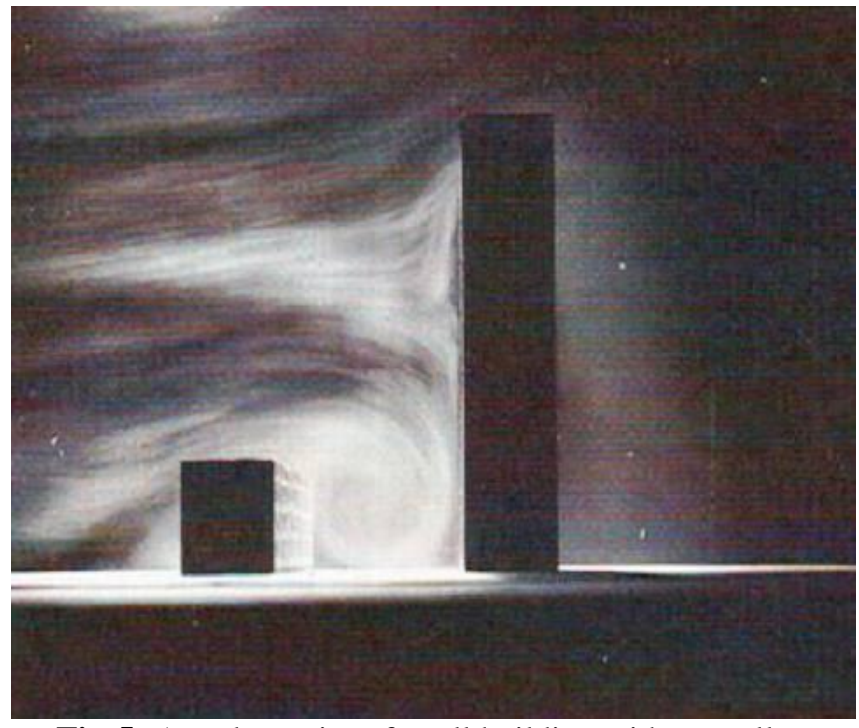

Fig-5: Aerodynamics of a tall building with a smaller building in the windward side. Source: [13].

\subsection{The Erosion Technique}

The erosion technique is useful for determining levels of windiness for various development projects. For the erosion tests the model is fixed on the turntable in the wind tunnel and the erodible material is spread on the base of the model. The speed at which bran particles get eroded (threshold speed of bran) is calibrated before the commencement of the erosion tests. The ratio between this speed and the speed at gradient height (when the bran particles get eroded for different speeds in the wind tunnel) is an indication of the discomfort factor [12]. Examples of wind tunnel tests carried out by the author [12] using the erosion technique in the University of Auckland ( UoA), New Zealand are shown in Figures 6, 7 and 8. The addition of an image processing system to the erosion technique by Eaddy [14] has considerably improved the versatility of the erosion technique.

View of a model of a neighborhood of tall and medium rise buildings with the addition of bran is shown in Fig. 6. An upstream view of the model in the wind tunnel with erosion patterns for $U_{\text {ref }}=5.75 \mathrm{~m} / \mathrm{s}$ is shown in Fig.7 [12].

The results of the erosion tests for different wind directions are presented in the form of bit map images with the addition of false colors for the contours of different wind speeds by the image processing system [14]. Fig. 8 shows a bit map image for the tall building in the central cluster $160 \mathrm{~m}$ high for $U_{\text {ref }}=2.45 \mathrm{~m} / \mathrm{s}$ [12]. The results generated by the image processing system in the form of colored patterns are easy to comprehend and at a glance many trends can be quickly recognized unlike data presented in a tabular format.

The outputs from the erosion tests that are of interest to consultants are the end result in the form of comfort category maps. The category maps show areas that are suitable or unacceptable for an intended activity after being compared with established criteria for comfort that are generated by the image processing system [14]. 


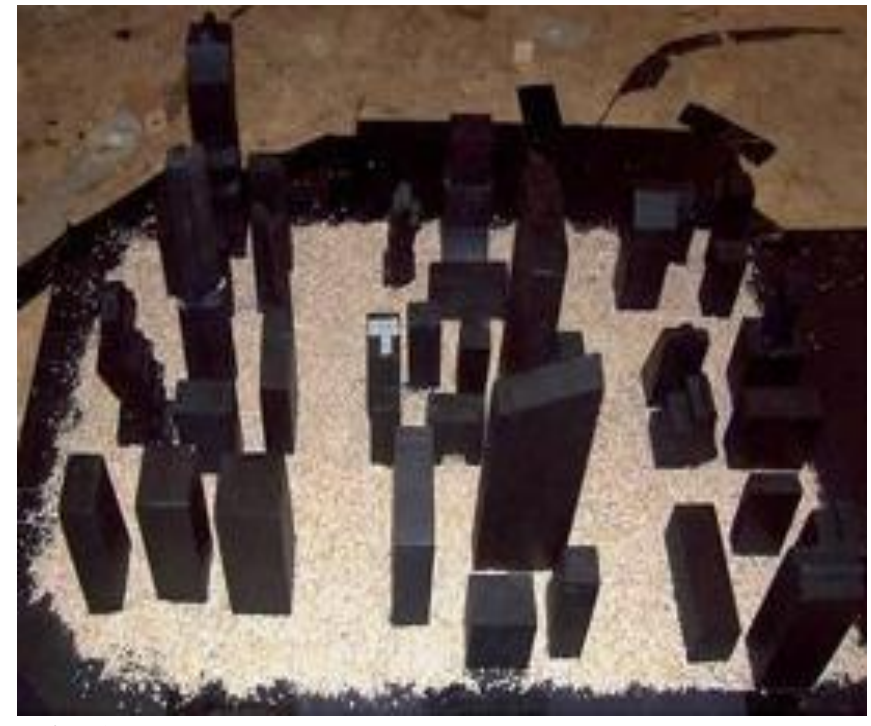

Fig-6: View of the model with the addition of the erodible material. Source: [12].

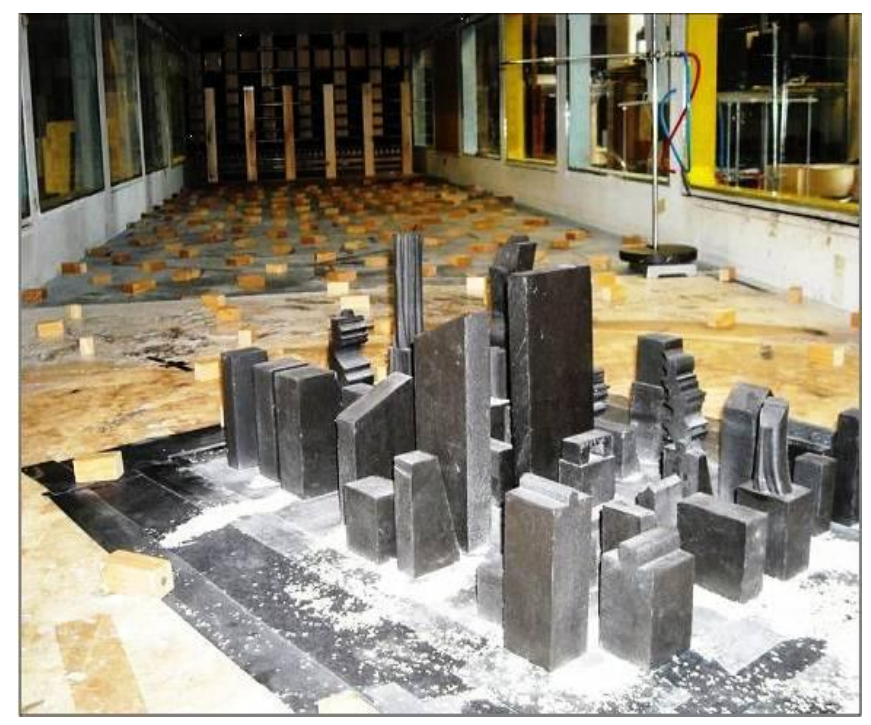

Fig-7: Upstream view of the model showing erosion patterns for $U_{\text {ref }}=5.75 \mathrm{~m} / \mathrm{s}$. Source: [12].

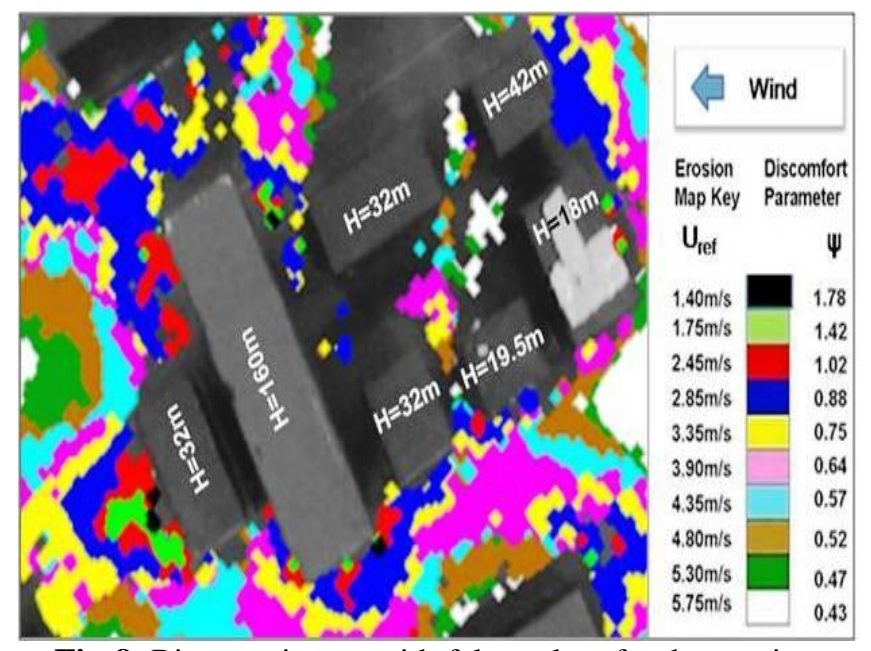

Fig-8: Bit- map image with false colors for the erosion contours. Source: [12].

\section{CONCLUSION}

In this review the state-of-art techniques for the measurement of PLWs have been discussed. Each method has its own advantages and disadvantages. Generally point methods provide quantitative information about the wind environment at specific points in a development whereas area methods provide information about wind flows over large areas. Initially to get an overall idea of the windy zones in a development project instruments and methods for assessing the wind environment over large areas in an existing or proposed development project may be used and thereafter point measurements may be employed for getting detailed information at specific points. The measurement capabilities of many of these techniques are being constantly improved with the advancement of computer hardware and software.

\section{ACKNOWLEDGEMENTS}

The author wishes to thank Professor Richard Flay, Tushar Guha, Alexander Judge, Nick Velychko and David Le Pelley for their assistance with the wind tunnel investigations.

\section{REFERENCES}

[1]. Yamada, M., Uematsu, Y., and Sasaki, R. (1996), “A visual technique for the evaluation of the pedestrian-level wind environment around buildings by using infrared thermography", Journal of Wind Engineering and Industrial Aerodynamics, Vol.65, pp.261-271.

[2]. Wu, H and Stathopoulos T. (1993), "Wind Tunnel Techniques for Assessment of Pedestrian-Level Winds", Journal of Engineering Mechanics, Vol.119, pp. 1920-1936. [3]. Outdoor Human Comfort and Its Assessment: The State of the Art [2004] American Society of Civil Engineers.

[4]. ASCE, (1999), "Manual of Practice for Wind Tunnel Studies of Buildings and Structures", Manual number 67, American Society of Civil Engineers.

[5]. Dantec Dynamics- Laser Doppler Anemometry (LDA), www.dantecdynamics.com- accessed on 20-8-2010.

[6]. Wu, H and Stathopoulos, T (1993), "InfraredThermography Technique for Pedestrian Wind Evaluation", Proceedings: Third Asia Pacific Symposium on Wind Engineering, Dec13-15, 1993, Hong Kong, pp. 967-972.

[7]. Kepka,B.J. (2010), “ Area assessment of a pedestrian wind speed environment using point wind speed measurements", Master of Building Science Thesis, Victoria University, Wellington.

[8]. Blocken,B, Stathopoulos, T and Carmeliet, J. ( 2008), “ Wind environmental condition in passages between two narrow perpendicular buildings", Journal of Aerospace Engineering, ASCE, Vol. 21, pp. 280-287.

[9]. Irwin, P.A. (1981), "A simple omnidirectional sensor for wind -tunnel studies of pedestrian level winds", Journal of Wind Engineering and Industrial Aerodynamics, Vol.7, pp.219-240.

[10]. Irwin, P.A., Baker,W.F., Korista,S., Weismantle, P.A., and Novak, L.C., (2006), "The Burj Dubai Tower- Wind Tunnel Testing of Cladding and Pedestrian Level", STRUCTURE magazine, pp. 47-51. 
[11]. TFI- Cobra Probe- Turbulent Flow Instrumentation, www.turbulent.com.au/Products/Cobra, accessed on 18-102010.

[12]. Mohan (2011). "Study of Pedestrian Level Wind Environment in the Vicinity of Tall Buildings", Ph.D. Thesis, Centre of Excellence in Disaster Mitigation and Management, Indian Institute of Technology, Roorkee, India.

[13]. BRE Digest 141(May1972)." Wind Engineering Around Tall Buildings".

[14]. Eaddy,M.and Flay,R.G.J.(1998), "Image Processing applied to pedestrian level wind investigations", IPENZ Transactions, Vol.25, No.1/EMCH.

\section{BIOGRAPHY}

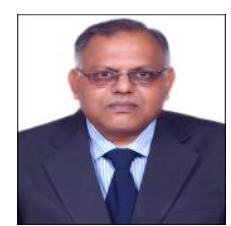

Prof. K. Mohan is working as a Senior Professor in the Gitam School of Architecture at Gitam University, Visakhapatnam. He did his B.Arch. from J.N.T.U. Hyderabad and M.Arch. from IIT Kharagpur. He did his Ph.D on Pedestrian Level Wind Environament in 2011 from IIT-Roorkee. 